\title{
La globalización y el impacto de la integración económica en el derecho administrativo colombiano*
}

\author{
Globalization and the impact of economic \\ integration on Colombian administrative law
}

\section{Margarita Cárdenas Poveda**}

\section{RESUMEN}

El derecho administrativo contemporáneo ha sido objeto de una transformación producto de los cambios socioeconómicos propios de la dinámica global y regional. Asi, estas líneas se proponen dilucidar brevemente el impacto de la globalización y de la integración económica en sus perspectivas regional e interregional en un derecho administrativo colombiano tradicionalmente nacional y dogmático, lo cual ha traido como consecuencia la tendencia a su homogeneización, respuesta que concretamente se observa en el mandato constitucional de integración latinoamericana y del Caribe, y más allá, la celebración de acuerdos de cooperación y de tratados de libre comercio.

PALABRAS CLAVE: Globalización, integración económica, integración regional e interregional, liberalización de mercado.

\begin{abstract}
The contemporary administrative law has been subject to a transformation caused by socioeconomic changes typical of global and regional dynamics. Thus, these lines attempt to elucidate, briefly, the impact of globalization and economic integration in regional and interregional perspectives on Colombian administrative law, traditionally national and dogmatic, which has led to the tendency to its homogenization, specifically regarding the constitutional mandate of Latin American and Caribbean integration, and beyond, the cooperation agreements and free trade agreements.
\end{abstract}

KEY WORDS: Globalization, economic integration, regional and interregional integration, market liberalization.

\footnotetext{
* Recibido: 25 de febrero de 2013. Aceptado: 2 de mayo de 2013.

** Jefa del Centro de Investigaciones Socio-Juridicas y del Área de Derecho Administrativo y Tributario de la Universidad de La Sabana, Colombia (margarita.cardenas@unisabana.edu.co).
} 


\section{Sumario}

1. Introducción

2. Desestatización de funciones a favor del mercado
A) Contractualización
B) Liberalización
c) Privatización
D) Fomento económico

3. Cambios en la interacción entre el Estado y el ciudadano

4. Uso de las TIC
A) Antecedentes y evolución
B) La figura del expediente electrónico
C) La sede electrónica
D) Las sesiones virtuales de comités, consejos, juntas y demás organismos colegiados
E) Publicación de actos administrativos

5. Conclusiones

\section{Introducción}

La globalización puede entenderse en sentido genérico como la creciente gravitación de los procesos económicos, sociales y culturales de carácter mundial sobre aquellos de carácter nacional o regional. ${ }^{1}$ Como consecuencia, los Estados tienden a implementar en sus legislaciones domésticas una cierta homogeneidad, por lo cual emprenden cambios en el orden jurídico interno, adaptándose a la tendencia del hemisferio.

La homogeneización del derecho administrativo producto de la globalización es una realidad que se inspira en una idea económica y social más antigua denominada "la aldea global", ${ }^{2}$ la cual proyecta un escenario en el que la accesibilidad de la información y la apertura de la sociedad del conocimiento son posibles mediante un sinnúmero de medios que revolucionan gradualmente la perspectiva política de los pueblos, y con ella el derecho que rige a los Estados contemporáneos.

Para identificar las tendencias de la globalización en el derecho administrativo colombiano y habiendo hecho referencia genérica al fenómeno aludido,

\footnotetext{
${ }^{1}$ Comisión Económica para América Latina y el Caribe (cepal). Globalización y desarrollo, cepal, Secretaría Ejecutiva, 2002, p. 13.

${ }^{2}$ La idea de aldea global se concibió en 1962 por el sociólogo Marshall McLuHAn, quien explicaba mediante este concepto que la humanidad estaría en contacto permanente con los sentidos extendidos y amplificados por la tecnología, lo que daría lugar a la idea de "ciudadanía global". Incluso hoy, algunos hablan de "sociedad híbrida", que habita entre lo virtual y lo real.
} 
descenderlo al caso nacional implica remitirse a los inicios de la tendencia globalizadora que, basada en parte en las ideas keynesianas, ${ }^{3}$ impregnó el surgimiento de una sociedad del capital cuya acelerada industrialización y crecimiento tuvieron como reacción en Colombia las medidas proteccionistas empleadas por el gobierno del presidente Carlos Lleras Restrepo en 1968. ${ }^{4}$ Con el fin de fomentar el desarrollo económico interno, este gobierno decidió limitar el flujo de importaciones con el objeto de impulsar la industria nacional y abrir campo a las exportaciones cafeteras y otros commodities. Posteriormente, hacia 1990 el gobierno de César Gaviria Trujillo decidió implementar la denominada "apertura económica" ${ }^{5}$ con la intención de modernizar el comercio nacional y bajar los aranceles para estimular las importaciones luego de un largo periodo de aislamiento del país ante el mercado internacional.

La apertura del mercado colombiano iniciada en estos años trajo a su vez retos importantes de gobernabilidad que, junto con el desarrollo de las telecomunicaciones y la infraestructura nacional, hizo que el Estado se planteara nuevas maneras de ejercer la función administrativa de forma eficiente mediante la delegación de algunas competencias administrativas por colaboración privada. ${ }^{6}$ En este contexto, las variables que se constituyen en expresión concreta de la globalización en el derecho administrativo colombiano pueden sintetizarse en a) la desestatización de funciones a favor del mercado; $b$ ) cambios en la inte-

\footnotetext{
${ }^{3}$ En la década de 1930 y como efecto de la crisis de 1929 se implementó el New Deal americano signado por el intervencionismo de Estado, apoyado en las teorías keynesianas sobre la demanda efectiva y el papel del gasto público. Cfr. Laufenburger, Henry. La intervención del Estado en la vida económica, Fondo de Cultura Económica, México, 1942, citado por Toвón Sanin, Gıberto. "Las privatizaciones en la economía colombiana", en Revista Ensayos de Economía, vol. 5, No. 8, 1994, p. 77.

${ }^{4}$ La estrategia de sustitución de importaciones, protección a la industria nacional y promoción de exportaciones desarrollada durante estos años habia permitido en su momento impulsar la industrialización. Sin embargo, la presencia marginal de las exportaciones colombianas en los mercados internacionales era una caracteristica de la economia colombiana que forzaba a un cambio en el modelo de desarrollo. Cfr. GaraY S., LUIS JoRge (dir.) y Quintero, LuIS Felpe et al. Colombia: estructura industrial e internacionalización 1967-1996, Departamento Nacional de Planeación, Bogotá, 1998, 631 pp.

${ }^{5}$ En agosto de 1990 inició su gobierno la administración Gaviria y en octubre de ese año el Consejo Nacional de Política Económica y Social (conPES) estableció un nuevo cronograma de ejecución de las reformas del régimen de importaciones y de la desgravación arancelaria para el periodo 1990-1994, mediante la cual se eliminaron las licencias previas de importación. Asimismo, se disminuyeron de 14 a 7 los niveles arancelarios con el ánimo de simplificar la estructura tarifaria, reduciéndose gradualmente el nivel de aranceles y la sobretasa. La desgravación se iniciaría en 1991, lo cual produjo un crecimiento de la demanda agregada interna a niveles superiores al 10\%, todo lo cual llevó a un significativo crecimiento del PIB. Cfr. GaraY S. op. cit.

${ }^{6}$ La delegación de la administración de una función pública es una modalidad de descentralización por colaboración que encuentra sustento constitucional suficiente, en la medida en que la carta política adscribe al legislador la competencia para determinar el régimen en que los particulares pueden cumplir funciones administrativas (artículo 210 CP). Por disposición legal, las actividades propias de la función pública ejercidas por particulares quedan sometidas a los principios que regulan la actividad administrativa, contenidos en el artículo 209 superior. CoRte Constitucional. Sentencia c-259 del 11 de marzo de 2008. M.P. Jaime Córdoba Triviño.
} 
racción entre el Estado y los ciudadanos, y c) el uso de las tecnologías de la información y las comunicaciones (TIC), las cuales serán abordadas a continuación.

\section{Desestatización de funciones a favor del mercado}

Esta variable se define como la reducción del espacio estatal a favor del mercado, como consecuencia de la transformación de las formas de intervención del Estado sobre la economía. ${ }^{7}$ La manifestación concreta de esta realidad se observa mediante diversas modalidades: a) la privatización; b) la liberalización; c) la contractualización, y d) el fomento económico. En esta medida, el Estado pasa de ser un prestador de servicios en el marco del Estado paternal y/o de bienestar, a un Estado regulador o policía cuyo espacio de actuación es reducido frente a la necesidad de expansión del mercado, ${ }^{8}$ concepto que cobrará suma relevancia tratándose de la integración de aliados económicos regionales e intrarregionales, como se abordará más adelante. A continuación se evidenciará la primera de esas modalidades.

\section{A) Contractualización}

En esta modalidad de desestatización, el ejercicio de la prestación de los servicios públicos se desarrolla ya no por parte de individuos vinculados laboralmente con el Estado, sino a través de terceros. Se gesta así una verdadera tercerización de la función administrativa mediante la cual la tradicional actividad administrativa imperativa desplegada mediante "acto unilateral" se transforma y complementa mediante una actividad consensual o "por contrato" de la administración en su sentido más amplio, como instrumento para alcanzar los fines y desarrollar las funciones del Estado. ${ }^{9}$

\footnotetext{
7 Restrepo Medina, Manuel Alberto et al. Globalización del derecho administrativo colombiano, Universidad del Rosario, Bogotá, 2010, colección Textos de Jurisprudencia, p. 47.

${ }^{8}$ Sin embargo, el fenómeno de la constitucionalización del derecho administrativo acaecido en los últimos años ha provocado el cambio de visión del mercado basado en la teoría económica de la Escuela de Chicago, abanderada de la doctrina del laissez faire, hacia la adopción de un modelo de economía social en el cual el principio de la libertad económica está limitado por el principio de la equidad social, la cual se propone eliminar las barreras de entrada al mercado y, con ello, el darwinismo económico contemporáneo, según el cual sólo sobrevive el más fuerte o quien tenga la posición dominante.

${ }^{9}$ La técnica contractual y el llamado fenómeno de contractualización de las relaciones jurídico-administrativas son una manifestación clara de los retos del Estado social de derecho. Es una técnica usada por los poderes públicos con muy distintos fines y motivos, desde los pactos políticos para la tramitación de reformas constitucionales o legislativas de gran importancia, que involucran al gobierno y a algunos sectores parlamentarios, hasta la refinanciación de multas en mora o los convenios de tipo laboral con los funcionarios públicos. Cfr. Molano López, Mario Roberto.
} 
De acuerdo con esta tendencia, el desarrollo de la función pública por particulares trasciende a un escenario más grande donde el Estado asume las competencias que no puede delegar en terceros, en el entendido de que la atribución de funciones administrativas a éstos está dada por la asignación constitucional que en forma exclusiva y excluyente se haga de la referida función a determinada autoridad. ${ }^{10}$

Así, “la atribución conferida al particular no puede llegar al extremo de que éste reemplace totalmente a la autoridad pública en el ejercicio de las funciones que le son propias", 11 pues la norma defiere a la autoridad

[...] la "regulación" de la atribución de funciones administrativas a particulares, y el señalamiento de las funciones específicas que serán encomendadas [...] potestad administrativa de determinar de manera concreta y particular dichas condiciones en un caso individual dado, a partir del régimen señalado por el legislador y para garantizar la efectividad del mismo. Esta regulación particular se lleva a cabo mediante la expedición del acto administrativo y un contrato ${ }^{12}$ (énfasis fuera de texto).

En este orden de ideas, la contractualización es más que una tendencia, al convertirse en requisito sine qua non para el ejercicio de funciones administrativas por particulares, según lo establecido por la Corte Constitucional:

Para conferir funciones administrativas a personas privadas mediante acto administrativo de carácter particular, no basta la expedición de dicho acto conforme a lo prescrito por la ley bajo examen, sino que es necesario, adicionalmente, que en todos los casos se suscriba con ellos un convenio mediante el cual expresamente se acepte la asignación de dicho ejercicio de funciones. Sólo de esta manera se preserva el principio de equidad, puesto que la autonomía de la voluntad particular es libre para aceptar la atribución individual de funciones administrativas, aun cuando ella resulte onerosa para el ciudadano. Así, no se imponen entonces cargas exorbitantes a determinadas personas privadas en particular. ${ }^{13}$

En esta línea, la evolución del Estado hace que la unilateralidad propia de la doctrina clásica de la función administrativa se aminore, dando lugar a la celebración de acuerdos comunes o contratos entre el Estado y el ciudadano, que

Transformación de la función administrativa (evolución de la administración pública), Pontificia Universidad Javeriana, Bogotá, 2005, Colección Profesores, p. 257.

${ }^{10}$ Corte Constitucional. Sentencia c-866 del 3 de noviembre de 1999. m.P. Vladimiro Naranjo Mesa.

1 Idem.

12 Idem

13 Idem. 
otrora significaba someter la voluntad imperativa de la administración a negociación, lo cual desnaturalizaba su objetividad. ${ }^{14}$

No debe perderse de vista que esta realidad jurídica y económica está en parte estimulada por las políticas fomentadas por el Banco Mundial y las Naciones Unidas en torno a la construcción gradual de un Estado con un régimen organizado y transparente de contratación pública como base para el desarrollo económico, principio denominado Public Procurement. ${ }^{15}$ Un ejemplo de la consagración de éste encuentra uno de sus asideros en el artículo 20 de la Ley 1150 de $2007,{ }^{16}$ según el cual cuando se celebren contratos o convenios financiados totalmente o en sumas superiores al cincuenta por ciento (50\%) con fondos de los organismos de cooperación, asistencia o ayudas internacionales, éstos podrán someterse a los reglamentos de tales entidades, autorizando la aplicación del derecho extranjero en la selección de contratistas dentro del territorio nacional. ${ }^{17}$

Asimismo, la contratación pública es un indicador de globalización en cuanto atrae la inversión extranjera en la implementación de proyectos que requieren la especialidad y capital de trabajo del sector extranjero, lo cual a su vez propende por la competitividad y el posicionamiento del mercado colombiano con impacto directo sobre el PIB. Esta afirmación además ha tomado fuerza por causa de la negociación y ratificación reciente de varios tratados de libre comercio celebrados con la Unión Europea y Estados Unidos, entre otros países, con el objeto de ampliar las relaciones comerciales y diplomáticas a un escenario contemporáneo internacional.

\section{Politicas públicas para la contratación estatal en un escenario de globalización}

Parte del efecto de este fenómeno sobre la contratación estatal estimuló la creación de un nuevo marco normativo e institucional mediante la política pública del Documento conPES 3249 de 2003,18 que influenciado por el Banco Mundial

\footnotetext{
14 Molano López, Mario Roberto. op. cit., p. 261.

${ }^{15}$ Esta directriz es de antaño una condición para los Estados, cuyo cumplimiento debe acreditarse para obtener préstamos de deuda pública externa como garantía de su pago y mecanismo para evitar la corrupción.

${ }^{16}$ Congreso de la República. Ley 1150 (16 de julio de 2007), "Por medio de la cual se introducen medidas para la eficiencia y la transparencia en la Ley 80 de 1993 y se dictan otras disposiciones generales sobre la contratación con Recursos Públicos", Diario Oficial, Bogotá, D.c., No. 46.691.

17 Restrepo Medina, Manuel Alberto et al. op. cit., p. 102.

18 Colombia. Consejo Nacional de Politica Económica y Social (conpes). Política de contratación pública para un Estado gerencial, Documento 3249, Bogotá, D.c., 20 de octubre de 2003.
} 
abanderó la política de contratación pública para un Estado gerencial. El objetivo general de esta política pública buscó "la eficiencia y la transparencia de la administración pública" mediante la vigencia de los principios de publicidad de las actuaciones, la capacitación de los funcionarios en política contractual y la planeación de los negocios en los cuales interviene el Estado. ${ }^{19}$

Esta nueva concepción trajo consigo la implementación de sistemas electrónicos para la contratación estatal mediante el Sistema de Información para la Vigilancia de la Contratación Estatal (sice), el cual operó hasta su derogación mediante la creación del Sistema Electrónico para la Contratación Pública (sECOP), como mecanismo de publicidad de las actuaciones precontractuales y contractuales de la administración, a través de la reglamentación contenida en el reciente Decreto 0734 de 2012. ${ }^{20}$

De igual manera, evidencia de la globalización en el derecho administrativo es la creación de la Agencia Nacional de Contratación Pública "Colombia Compra Eficiente" a través del mismo Decreto, cuyo objeto es desarrollar e impulsar políticas públicas y herramientas orientadas a la organización y articulación de los partícipes en los procesos de compras y contratación pública, con el fin de lograr una mayor eficiencia, transparencia y optimización de los recursos del Estado. ${ }^{21}$ La armonización de este frente, perteneciente al régimen de compras del sector público, también ha resultado un instrumento para expandir el comercio internacional, la integración económica y, con ella, una manifestación del proceso globalizador.

Lo anterior ha hecho que el sector inversionista extranjero tenga un mayor acercamiento e interés en el desarrollo de sus negocios en Colombia, posibilitados en gran medida por los tratados que en materia económica se han celebrado recientemente con la Unión Europea y Estados Unidos. Empresas de los más variados sectores perciben estos adelantos como una apertura de la administración pública y el derecho administrativo a las necesidades de expansión de la economía a escala mundial y regional.

\footnotetext{
${ }_{19}$ De acuerdo con el conPEs, la lucha contra la corrupción impulsada por esta política se hizo necesaria en tanto una encuesta del Banco Mundial mostró que los funcionarios públicos entrevistados declararon que en el $49.7 \%$ de las licitaciones públicas en Colombia se realizaban pagos adicionales para asegurar la adjudicación de contratos, percepción corroborada por los empresarios, que en un 62\% coincidieron en que "siempre o casi siempre" las empresas recurrían a pagos extraoficiales para ganar concursos o licitaciones públicas. Op. cit., p. 6.

20 Colombia. Departamento Nacional de Planeación. Decreto 0734 (13 de abril de 2012), "Por el cual se reglamenta el Estatuto General de Contratación de la Administración Pública y se dictan otras disposiciones", Diario Oficial, Bogotá, D.C., No. 48.400.

${ }^{21}$ Colombia. Departamento Administrativo de la Función Pública. Decreto 4170 (3 de noviembre de 2011), "Por el cual se crea la Agencia Nacional de Contratación Pública -Colombia Compra Eficiente-, se determinan sus objetivos y estructura", Diario Oficial, Bogotá, D.c., No. 48.242, artículo 2.
} 


\section{B) Liberalización}

La desestatización como parte de la globalización e integración se manifiesta también en la desmonopolización de actividades a favor del mercado nacional e internacional, lo cual abre la posibilidad a los particulares de desarrollar de manera concurrente con el Estado actividades de servicio público. Este hecho suscita a su vez la creación de agencias de regulación que desde la Constitución de 1991, en su artículo 334, ${ }^{22}$ radica en cabeza del Estado la dirección de la economía y prevé la intervención estatal en todas las actividades económicas para conseguir "el mejoramiento de la calidad de vida de los habitantes, la distribución equitativa de las oportunidades y beneficios del desarrollo y la preservación de un ambiente sano", ${ }^{23}$ entre otros propósitos. Así, las comisiones de regulación son organismos técnicos encargados de fijar y monitorear las tarifas de los servicios públicos prestados por particulares y de imponer estándares mínimos para su prestación como una tendencia propia de la globalización.

En el caso de los servicios públicos domiciliarios, las comisiones de regulación nacieron desde la expedición de la ley 142 de 1994, inspiradas en parte en el movimiento regulatorio como técnica de intervención del Estado en la economía que comenzó a implementarse en los Estados Unidos desde fines del siglo XIX con la intención de evitar distorsiones de algunos mercados específicos en los que se observaba la formación de monopolios y, en general, restricciones a la libre competencia. ${ }^{24}$

Como respuesta a la liberalización a favor del mercado, se observa que el Estado pasó de ser un prestador de servicios a un Estado regulador, que bien puede adoptar alguno de los tres modelos regulatorios existentes mediante la ley 142 citada: a) régimen de libertad; b) libertad vigilada, o c) libertad regulada; lo anterior de acuerdo con las características del mercado relevante. Así, la comisión reguladora correspondiente puede establecer topes máximos y mínimos tarifarios de obligatorio cumplimiento por parte de las empresas de determinado sector económico. Igualmente, podrá definir las metodologías para la determinación de tarifas si conviene aplicar el régimen de libertad regulada o vigilada.

\footnotetext{
22 "La dirección general de la economía estará a cargo del Estado. Éste intervendrá, por mandato de la ley, en la explotación de los recursos naturales, en el uso del suelo, en la producción, distribución, utilización y consumo de los bienes, y en los servicios públicos y privados, para racionalizar la economía con el fin de conseguir en el plano nacional y territorial, en un marco de sostenibilidad fiscal [...]".

${ }^{23}$ Corte Constitucional. Sentencia c-186 del 16 de marzo de 2011. m.P. Humberto Antonio Sierra Porto.

${ }^{24}$ GIL Botero, EnRIoue. "La valoración jurídica de las manifestaciones normativas de las comisiones de regulación: los sutiles límites entre la función administrativa que les es propia y las funciones legislativa y judicial", en Revista Digital de Derecho Administrativo, No. 3, segundo semestre de 2009, p. 10.
} 
Estos tres regímenes de regulación de mercados permiten al Estado mantener un control sobre éste para evitar la distorsión del mismo y asegurar su democratización, siguiendo de cerca un modelo de economía social ${ }^{25}$ y dejando de lado las concepciones del dejar hacer ${ }^{26}$ económico, si bien se propende por el desarrollo mancomunado de las regiones y la calidad de vida. De esta manera, la agencia reguladora sólo intervendrá un mercado cuando sea necesario para asegurar la libre concurrencia de agentes, impidiendo las barreras de entrada o de salida y las conductas de dominación ejercidas por uno de ellos, con lo cual se evitarán conductas predatorias entre los integrantes del mercado.

En relación con la regulación del mercado y la integración económica, es importante mencionar que en Colombia el régimen de libertad es la regla general, por lo cual es premisa que el Estado sólo intervendrá en la economía cuando sea estrictamente necesario para proteger los intereses de la parte que se encuentre en desventaja. Este escenario también ha contribuido a que el sector inversionista se persuada de establecer negocios en la región.

\section{c) Privatización}

Otra de las políticas económicas propias de la globalización económica es la privatización o desnacionalización, la cual responde a una política mundial inscrita en la era neoliberal que tomó fuerza a mediados de la década de los años setenta y se profundizó en la década de los ochenta como una respuesta a la crisis capitalista de finales del siglo xx. ${ }^{27}$ En términos jurídicos, se define como el retiro del Estado de las actividades de prestación de bienes y servicios. ${ }^{28}$

De acuerdo con la jurisprudencia de la Corte Constitucional colombiana,

[...] la privatización es un fenómeno jurídico que consiste en que un patrimonio de naturaleza pública es enajenado a particulares, de tal manera que se trueca en priva-

\footnotetext{
25 El sistema de la economía social de mercado (ESM) surge del intento consciente de sintetizar todas las ventajas del sistema económico de mercado: fomento de la iniciativa individual, productividad, eficiencia, tendencia a la autoregulación, con los aportes fundamentales de la tradición social-cristiana de solidaridad y cooperación, que se basan necesariamente en la equidad y la justicia en una sociedad. Cfr. RESICO, MARCELO F. Introducción a la economía social de mercado, Edición Latinoamericana, Konrad Adenauer Stiftung, Buenos Aires, 2010, p. 108.

${ }^{26}$ El laissez faire, de acuerdo con la Escuela de Chicago o monetarista, es la concepción según la cual el Estado no debe ser rector de la economía, pues la mano invisible -como se ha denominado a las fuerzas y leyes propias del mercado- lo autorregula de manera natural, por lo cual no es necesaria su injerencia, relegándolo a ejercer una conducta pasiva, catalogado entonces como gendarme o vigilante nocturno. Cfr. Ávila y Lugo, José. Introducción a la economía, 3a. ed., UnAm, México, 2004, p. 105.

27 Tobón Sanin. op. cit.

${ }^{28}$ Restrepo Medina, Manuel Alberto et al. Globalización del derecho administrativo colombiano, cit., p. 59.
} 
do [...] comporta un cambio en la titularidad de ese patrimonio, que siendo estatal, pasa a manos de los particulares, y debe aquélla responder a políticas que miran por la realización de los principios de eficiencia y eficacia de la función pública y enmarcarse dentro de los criterios del artículo 60 de la Carta. ${ }^{29}$

De esta manera, la eficiencia y eficacia de la función pública son los móviles de esta tendencia. De acuerdo con la exposición de motivos de las normas citadas en el presente escrito, la modernización - o contemporaneidad- del derecho administrativo propio de estas disposiciones lleva implícita la vigencia de los principios de la función administrativa del debido proceso: igualdad, imparcialidad, buena fe, moralidad, participación, responsabilidad, transparencia, publicidad, coordinación, eficacia, economía y celeridad. ${ }^{30}$

La diferencia entre la privatización de entidades públicas y el desempeño de función pública por particulares radica en que la asunción de funciones administrativas por los particulares "es un fenómeno que no conlleva en modo alguno cambio en la titularidad del patrimonio estatal, significa simplemente la posibilidad dada a aquéllos de participar en la gestión de los asuntos administrativos, en las condiciones y bajo los parámetros señalados por la Constitución, la ley y los reglamentos". ${ }^{31}$ Mientras que el concepto de privatización lleva consigo el de transferencia o enajenación del capital público y de la gestión de la actividad a manos privadas.

Esta tendencia se observa en la despublificación que comporta la devolución de una cierta actividad a la sociedad, dejada definitivamente por el ente administrativo al sector privado para procurar su eficiencia, que involucra tres modalidades de privatización: una funcional, otra institucional y otra técnica; esta última considerada como sustancial, pues incorpora técnicas privadas de gestión propias de una lógica empresarial a dicha actividad.

\section{D) Fomento económico}

Otro de los ejes sobre los cuales se desarrolla el tema bajo estudio es la política de fomento liderada por el Estado, a través de la cual éste se propone atraer la inversión extranjera y, a su vez, ser eficiente en lo que se ha llamado "la administración económica" ${ }^{32}$

\footnotetext{
${ }^{29}$ Corte Constitucional. Sentencia c-866.

30 Colombia. Congreso de la República. Ley 1437 (18 de enero de 2011), "Por la cual se expide el Código de Procedimiento Administrativo y de lo Contencioso Administrativo", Diario Oficial, Bogotá, D.c., No. 47.956, artículo 3.

${ }^{31}$ Idem.

32 Restrepo Medina, Manuel Alberto et al. op. cit., p. 60.
} 
De acuerdo con la tendencia que algunos denominan como "intervención indirecta en la economía”, la globalización hace que los Estados implementen incentivos de toda índole que protejan y con ello atraigan el desarrollo económico mediante estrategias para la estabilidad de las inversiones. Así, se despliegan incentivos tributarios para ciertos sectores de la economía y hasta contratos que previenen la expropiación indirecta de la inversión mediante la indemnización por parte del Estado ${ }^{33}$ en caso de cambios legislativos que la hagan menor o que incluso la conviertan en ilusoria.

Esto a su vez hace parte de un concepto más grande definido como "la administración indirecta”, entendida como el conjunto de actuaciones previas, blandas en cuanto no vinculantes y recíprocas con las cuales la administración busca incidir en la formación de la voluntad de los ciudadanos para adecuar sus comportamientos a la expectativa estatal. ${ }^{34}$ Esta política actúa mediante actos que ordenan, prohíben o configuran una situación jurídica que tiene por objeto persuadir a sus destinatarios, frente a lo cual surge el deber del Estado de informar a los administrados sobre sus derechos y a la vez sobre las sanciones que les sobrevendrían en caso de obrar de una u otra forma.

El efecto de esta modalidad de globalización es ni más ni menos que el nacimiento de un Estado cooperativo cuyo propósito es neutralizar los riesgos que lleven a conflictos con los diferentes grupos sociales; en el caso del fomento, con el sector inversionista, buscando comportamientos voluntarios inducidos que beneficien el desarrollo económico del país y, más aún, de la región, para llevar a cabo una paulatina integración con el mercado global.

\section{a. Integración económica regional e interregional}

Lo anterior lleva a repensar la forma en que los Estados administran sus economías, e incluso a estructurar una integración económica de carácter regional e interregional, cuya manifestación se concreta en acuerdos bilaterales o multilaterales que tienen como fin apalancar el crecimiento de las regiones, que en el caso de Latinoamérica y el Caribe se encuentra en vía de desarrollo. Curiosamente, luego de las crisis económicas surgidas en el viejo continente y en Estados Unidos, América Latina ha mostrado cifras de crecimiento sostenidas, lo

\footnotetext{
33 Según F. CASTILlo y Javier Rincón estos contratos, denominados "de estabilidad jurídica", son en realidad contratos de seguro donde el asegurador es el Estado y el inversionista es el asegurado. Cfr. CAstillo, F. y Rincón S., Javier G. La estabilidad jurídica, bienestar económico y servicio público, Javegraf, Bogotá, 2009, citado por RestRePo MEDINA, Manuel Alberto et al. op. cit., p. 61.

${ }^{34}$ Molano López, Mario Roberto. op. cit., p. 271.
} 
cual ha impactado positivamente en la decisión del sector inversionista europeo y estadounidense de traer un flujo de capital importante a esta zona, lo cual se evidencia con la creación exponencial de sucursales de sociedades extranjeras y de inversión extranjera directa en los países latinos.

Así, la integración regional de base económica es una herramienta fundamental con que cuentan los países de este hemisferio para enfrentar los retos que impone la globalización, entendiendo por ésta un fenómeno económico complejo con incidencia dominante en el intercambio de bienes y servicios, la inversión extranjera y la circulación del capital. ${ }^{35}$ Como parte de la evolución de la función regulatoria de los Estados sobre la economía, las administraciones han dado especial prioridad a la celebración de tratados de libre comercio como andamiaje para posibilitar dicho fenómeno, e integrar la movilidad de los capitales, de las personas y de las tecnologías mediante la promoción a las exportaciones, teniendo como fin último la creación de un mercado global donde las ventajas competitivas de unos se fortalezcan con las de otros para impulsar conjuntamente la región mediante alianzas, mercados externos y financiación con instituciones como en el Fondo Monetario Internacional o el Banco Mundial.

En esta medida, la integración regional es un baluarte que combina la coordinación de políticas regionales, la liberación económica de las fronteras y, con ello, la eliminación de las desigualdades y/o diferencias de mercados, la cual es, "en efecto, considerada como una etapa o una alternativa a la globalización, según la confianza que se le otorgue a los mecanismos de mercado para integrar los hombres, las firmas y desarrollar los territorios", como se menciona en la Carta de las Naciones Unidas. En este sentido, una reacción a la globalización es la efectiva integración de mercados que en principio funcionaron separadamente, pero que a través de su interfuncionalidad institucional y normativa hacen que las empresas y/o filiales de las sociedades multinacionales de los países terceros, una vez instaladas y reconocidas en un país, sean reconocidas en toda la región. ${ }^{36}$ Más allá, se plantea la deslocalización como el reto más importante, entendida ésta como "la libre circulación de bienes entre territorios desarrollados de forma desigual donde las condiciones de costos son completamente diferentes, mientras que el mercado permanece siendo único, enorme y creciente". ${ }^{37}$

\footnotetext{
${ }_{35}$ Rincón CÁrdenas, ERIck et al. "Fortalecimiento de la integración regional por medio de los acuerdos de asociación, un presupuesto para una adecuada inserción de los países en vía de desarrollo en el contexto de globalización -caso CAN y CE-", Tratado de libre comercio. La integración comercial y el derecho de los mercados, Universidad de Rosario, Bogotá, 2006.

${ }^{36}$ Crochet, Alain. "Mondialistation et regionalization: les déterminants exogénes de L'AlenA", en Integration dans les Amériques -Dix ans D'ALENA, textos reunidos y presentados por Martine Azuelos, María Eugenia Cosío-Zavala, JeanMichel Lacroix, Presses Sorbonne Nouvelle, París, 2004, p. 142, citado por idem.

${ }^{37}$ Idem.
} 


\section{b. El mandato constitucional de integración latinoamericana $y$ del Caribe}

La carta política de 1991 ya establecía el mandato elevado al orden constitucional de efectuar una efectiva integración con la región para propender por "el desarrollo de las entidades territoriales y de su autonomía, así como la promoción de procesos de intercambio social, cultural o económico" ${ }^{38}$ En efecto, "[l]a Corte Constitucional ha indicado que la profundización de las relaciones en zonas de frontera guarda correspondencia con el ideal integracionista que inspira las relaciones internacionales según el texto de la Constitución".

En efecto, la importancia de la integración económica se manifiesta concretamente en los departamentos y municipios ubicados en zonas de frontera, los cuales pueden adelantar directamente con las entidades territoriales limítrofes del país fronterizo y que se encuentran en el mismo nivel, programas de cooperación e integración a efectos de fomentar el desarrollo comunitario, la prestación de servicios públicos y la preservación del medio ambiente. ${ }^{39}$ En desarrollo de lo anterior, el numeral 2 del artículo 300 constitucional establece que le corresponde a las asambleas departamentales expedir las disposiciones relacionadas con las zonas de frontera. Asimismo, el artículo 337 prevé que la ley podrá establecer para las zonas de frontera regímenes especiales en materia económica y social que se orienten a promover el desarrollo de las mismas.

En este sentido, aunque en principio el ámbito geográfico de las facultades constitucionales mencionadas se limita al desarrollo fronterizo, el preámbulo constitucional también se enfoca en generar integración con otras naciones, bajo los principios de reciprocidad, equidad y conveniencia nacional. De esta manera, el legislador colombiano tiene amplias facultades para generar acuerdos de cooperación y liberalización de mercados que propendan por generar desarrollo, con las únicas limitaciones que le imponen la soberanía nacional y las competencias de las autoridades nacionales y territoriales en su respectiva jurisdicción.

\section{Cambios en la interacción entre el Estado y el ciudadano}

Otra evidencia de movimiento globalizador e integracionista en el derecho administrativo y en el ejercicio de la función administrativa es el necesario cambio

\footnotetext{
38 Corte Constitucional de Colombia. Sentencia c-303 del 25 de abril de 2012, m.P. Mauricio González Cuervo.

${ }^{39}$ Op. cit.
} 
de las técnicas de interacción del Estado con los ciudadanos, mediante la simplificación de procedimientos surtidos ante las autoridades administrativas. Como ha quedado patente en este estudio, el fomento a la eficiencia de la gestión pública es uno de los principales objetivos de este fenómeno, lo cual se expresa de manera concreta mediante la reciente regulación del Decreto-Ley Antitrámites -019 de 2012-, ${ }^{40}$ norma expedida en uso de facultades especiales conferidas mediante la Ley 1474 de $2011,{ }^{41}$ orientada a reducir la intervención policiva del Estado sobre el comportamiento de los particulares mediante la eliminación de procedimientos que de antaño dilataban las actuaciones de los administrados ante el Estado.

El antecedente de esta norma se encuentra en la política antitrámites y de “Gobierno en línea”, la cual se llevó a cabo mediante la Ley 962 de $2005^{42}$ y reglamentada parcialmente mediante el Decreto 1151 del 14 de abril de 2008, ${ }^{43}$ cuyas fases fueron:

a) La identificación de trámites y servicios, fase en que cada entidad del Estado debió levantar y revisar la información detallada de los trámites y servicios existentes a su cargo para su posterior inscripción en el Sistema Único de Información de Trámites (suit), el cual opera a través del portal del Estado colombiano: www.gobiernoenlinea.gov.co.

b) La racionalización de trámites y servicios, mediante la cual se ordenó implementar estrategias efectivas de simplificación, automatización y optimización de los procesos y procedimientos en orden a crear trámites simples, eficientes, directos y oportunos.

c) El estudio e identificación de cadenas de trámites, mediante el cual las entidades públicas debieron realizar un análisis transversal para diagnosticar puntos críticos y asociaciones comunes intra e inter-sectoriales correlacionados con los servicios de otras entidades del Estado, eliminando así la duplicidad de información, pasos innecesarios y altos costos de transacción.

40 Colombia. Presidencia de la República. Decreto-Ley 019 (10 de enero de 2012), "Por el cual se dictan normas para suprimir o reformar regulaciones, procedimientos y trámites innecesarios existentes en la administración pública", Diario Oficial, Bogotá, D.C., No. 48308.

${ }^{41}$ Colombia. Congreso de la República. Ley 1474 (12 de julio de 2011), "Por la cual se dictan normas orientadas a fortalecer los mecanismos de prevención, investigación y sanción de actos de corrupción y la efectividad del control de la gestión pública", Diario Oficial, Bogotá, D.c., No. 48.128.

${ }^{42}$ Colombia. Congreso de la República. Ley 962 (8 de julio de 2005), "Por la cual se dictan disposiciones sobre racionalización de trámites y procedimientos administrativos de los organismos y entidades del Estado y de los particulares que ejercen funciones públicas o prestan servicios públicos", Diario Oficial, Bogotá, D.c., No. 46.023, de 6 de septiembre de 2005.

${ }^{43}$ Colombia. Presidencia de la República. Decreto 1151 (14 de abril de 2008), "Por el cual se establecen los lineamientos generales de la Estrategia de Gobierno en Línea de la República de Colombia, se reglamenta parcialmente la Ley 962 de 2005, y se dictan otras disposiciones", Diario Oficial, Bogotá, D.c., No. 46.960. 
d) La implementación de ventanillas únicas, sitios virtuales desde los cuales se gestiona de manera integrada la realización de trámites que están en cabeza de una o varias entidades, proveyendo la solución completa al interesado. ${ }^{44}$

e) La concreción del portal del Estado colombiano, mediante la fase de "Democracia en línea”, que incorpora la información, servicios y trámites del Estado de las fases anteriores.

Todas las entidades que conforman la administración pública en Colombia debieron ajustarse a los parámetros aludidos en un margen de tiempo específico otorgado por autorización de ley. Éste sería un eslabón importante de la modernización del Estado, que ha devenido en la interactividad tecnológica y uso de las TIC, tratado en el próximo acápite, y que ha cambiado la forma en la que el Estado interactúa con sus administrados.

\section{Uso de las TIC}

Otra de las manifestaciones de la globalización del derecho administrativo colombiano se encuentra en la incorporación gradual de las tecnologías de la información y las comunicaciones TIC a la ejecución de la función administrativa. Uno de los programas principales usados en pos de modernizar la función desempeñada por todas las autoridades del sector central de la administración se denomina "Gobierno en línea", consolidado como una herramienta de servicio al ciudadano que facilita su participación a través de mecanismos flexibles y ágiles que permitan una retroalimentación permanente con la administración en la prestación de servicios y la atención de peticiones, quejas y reclamos o recursos $(\mathrm{PQR}), \mathrm{y}$ la consulta de trámites ante la administración.

Asimismo, con la expedición del nuevo Código de Procedimiento Administrativo y de lo Contencioso Administrativo (Ley 1437 de 2012), la ciudadanía puede presentar peticiones, quejas y reclamos o recursos y sin necesidad de apoderado, ${ }^{45}$

\footnotetext{
${ }^{44}$ Mediante esta fase se lograron implementar, entre otros, el trámite electrónico de autorizaciones, permisos, certificaciones o vistos buenos previos sin documentos físicos; pago electrónico para los recaudos; sustitución de formularios físicos por formularios virtuales; atención al usuario 7x24 horas; operación a través de certificados digitales; seguridad y transparencia del proceso; eficiencia operativa, y minimizar el desplazamiento para realización de trámites. "Cuáles son las fases o etapas de la política antitrámites" [Artículo Web]. Disponible en: http://www. gobiernoenlinea.gov.co/web/guest/encyclopedia/-/wiki/Enciclopedia\%20del\%20Estado/Cu\%C3\%A1les+son+las+fa ses+o+etapas+de+la+Pol\%C3\%ADtica+Antitr\%C3\%A1 mites.

45 Sobre las normas relativas al derecho de petición por medios electrónicos véanse los artículos 15 y ss., ibidem. Este capítulo fue declarado inexequible con efectos diferidos hasta el 31 de diciembre de 2014 mediante sentencia c-818
} 
así como obtener información y orientación acerca de los requisitos para tal efecto, por cualquier medio tecnológico o electrónico disponible en la entidad, aun por fuera de las horas de atención al público. ${ }^{46}$ lgualmente, las autoridades tienen el deber de establecer un sistema de turnos acorde con las necesidades del servicio y las nuevas tecnologías, para la ordenada atención de peticiones, quejas, denuncias o reclamos, para lo cual deben adoptar medios tecnológicos para el trámite y resolución de peticiones, y permitir el uso de medios alternativos para quienes no dispongan de aquéllos. ${ }^{47}$

Al mismo tiempo, la Ley obliga a las autoridades administrativas a mantener a disposición de toda persona, información completa y actualizada en el sitio de atención y en la página electrónica, y suministrarla a través de los medios impresos y electrónicos de que disponga, por medio telefónico o por correo. ${ }^{48}$

De la misma manera, en lo relacionado con la tecnificación del procedimiento administrativo general contenido en esta norma, el artículo 35 menciona que éste se adelantará por escrito, verbalmente o por medio electrónico, limitando este último en el caso de las actuaciones de oficio, las cuales se harán por este medio cuando la ley expresamente lo autorice para garantizar la notificación y ejercicio del derecho de defensa por parte del interesado o de terceros afectados por la decisión, pudiendo enviar comunicaciones al correo electrónico de éstos de no haber otro medio más eficaz. ${ }^{49}$

Específicamente, el artículo iv de la Ley 1437 se concentra en la utilización de medios electrónicos en el procedimiento administrativo, del cual interesa resaltar lo contenido en el artículo 54 del mismo, según el cual las peticiones de información y consulta se entenderán hechas en término, siempre que hubieran sido registrados hasta antes de las doce de la noche. Asimismo, en términos probatorios resulta importante la disposición del artículo 55, por medio del cual los documentos públicos o sus copias contenidos en archivos y medios electrónicos que los autorizan o suscriben se entienden auténticos para todos los efectos legales. ${ }^{50}$ lgualmente, la notificación por medios electrónicos podrá realizarse

de 2011 por vicios de forma, pues a través de este fallo la Corte Constitucional instó al Congreso de la República para expedir una Ley Estatutaria contentiva de estas normas.

${ }^{46}$ Ibidem, artículo 5.

47 Ibidem, artículo 7.

${ }^{48}$ Sobre el deber de información al público véase el artículo 8, ibidem.

49 Ibidem, inciso 2 del artículo 37.

${ }^{50}$ Antecedente de este artículo está en lo contenido en el artículo 19 de la Ley 527 de que se habla más adelante, donde se dispone perentoriamente que los mensajes de datos serán admisibles como medio de prueba y su fuerza probatoria es la otorgada en las disposiciones del Código de Procedimiento Civil para los demás medios probatorios. Cfr. Villabiba Pérez, Francisca et al. "Panorama general del derecho administrativo en Colombia (2004)", en González VARAs-Ibã̃ez, SAntiago (dir.). El derecho administrativo iberoamericano, InAP, Granada, 2005, colección Estudios y Comentarios, No. 9, p. 217. 
cuando el administrado así lo ha autorizado, y se surte a partir de la fecha y hora en que éste accede al acto administrativo. Todo lo anterior está en concordancia con el artículo 57, que autoriza la expedición de actos administrativos en forma electrónica siempre y cuando se asegure su autenticidad, integridad y disponibilidad.

\section{A) Antecedentes y evolución}

Estos avances legislativos ya tenían antecedentes en normas expedidas en la década de 1990, mediante la Ley 270 de 1996 sobre Administración de Justicia, que estableció por vez primera en la legislación colombiana la validez y eficacia del documento electrónico, ${ }^{51}$ facultando a la rama judicial para hacer uso de los medios tecnológicos disponibles para el ejercicio de sus funciones, lo cual fue ratificado posteriormente mediante la Ley 527 de $1999^{52}$ sobre Acceso y Uso de los Mensajes de Datos, la cual establece enfáticamente en su artículo 5, en lo relativo al reconocimiento de éstos, que "no se negarán efectos jurídicos, validez o fuerza obligatoria a todo tipo de información por la sola razón de que esté en la forma de mensajes de datos", motivado en la desconfianza que en aquella época generó la conservación de la información en ese formato, dada su vulnerabilidad y propensión a la falsificación.

Posteriormente, la Ley 594 de 2000, en su artículo 19,,$^{53}$ permitió a las entidades del Estado incorporar tecnologías de avanzada en la administración y

51 Colombia. Congreso de la República. Ley 270 (7 de marzo de 1996), "Ley Estatutaria de la Administración de Justicia", Diario Oficial, Bogotá, D.C., No. 42.745, de 15 de marzo de 1996. Artículo 95. "Tecnología al Servicio de LA ADMinistRación DE JUSTICIA. El Consejo Superior de la Judicatura debe propender por la incorporación de tecnología de avanzada al servicio de la administración de justicia. Esta acción se enfocará principalmente a mejorar la práctica de las pruebas, la formación, conservación y reproducción de los expedientes, la comunicación entre los despachos y a garantizar el funcionamiento razonable del sistema de información. Los juzgados, tribunales y corporaciones judiciales podrán utilizar cualesquier medios técnicos, electrónicos, informáticos y telemáticos, para el cumplimiento de sus funciones. Los documentos emitidos por los citados medios, cualquiera sea su soporte, gozarán de la validez y eficacia de un documento original siempre que quede garantizada su autenticidad, integridad y el cumplimiento de los requisitos procesales. Los procesos tramitados con soporte informático garantizarán la identificación y el ejercicio de la función jurisdiccional por el órgano que la ejerce, así como la confidencialidad, privacidad, y seguridad de los datos de carácter personal que contengan en los términos que establezca la ley".

52 Colombia. Congreso de la República. Ley 527 (18 de agosto de 1999), "Por medio de la cual se define y reglamenta el acceso y uso de los mensajes de datos, del comercio electrónico y de las firmas digitales, y se establecen las entidades de certificación y se dictan otras disposiciones", Diario Oficial, Bogotá, D.c., No. 43.673, de 21 de agosto de 1999.

53 Colombia. Congreso de la República. Ley 594 (14 de julio de 2000), "Por medio de la cual se dicta la Ley General de Archivos y se dictan otras disposiciones", Diario Oficial, Bogotá, D.c., No. 44.093. "Artículo 19. Las entidades del Estado podrán incorporar tecnologias de avanzada en la administración y conservación de sus archivos, empleando cualquier medio técnico, electrónico, informático, óptico o telemático, siempre y cuando cumplan con los siguientes requisitos: a) Organización archivística de los documentos; b) Realización de estudios técnicos para la adecuada decisión [...] Parágrafo 10. Los documentos reproducidos por los citados medios gozarán de la validez y eficacia del 
conservación de sus archivos, fomentando los sistemas de información que hoy tienen estas autoridades y motivando con ello el diseño de software para uso privativo de la administración.

\section{B) La figura del expediente electrónico}

La globalización del derecho administrativo también encuentra un asidero importante tratándose de la regulación del denominado expediente electrónico, como "conjunto de documentos electrónicos correspondientes a un procedimiento administrativo". En otro tiempo esta norma no hubiera podido concebirse por la costumbre cartularia o escrita del derecho tradicional, rebatida por previsiones como las del artículo 59 de la Ley aludida, según el cual el foliado de este expediente debe realizarse mediante un índice electrónico firmado digitalmente por la autoridad, garantizando con éste su integridad y recuperación. Así, actualmente la principal preocupación de la ley no es el medio que contenga la información, sino la viabilidad del mismo para consultarla cuando se requiera, lo cual se observa en la obligación de conservar copias de seguridad periódicas.

\section{c) La sede electrónica}

Simultáneamente, se prevé en el artículo 60 del Código mencionado que "toda autoridad deberá tener al menos una dirección electrónica” con garantía de la calidad, seguridad, disponibilidad, accesibilidad, neutralidad e interoperabilidad de la información contenida en ésta. Esta norma, a su vez, autoriza las sedes electrónicas comunes o compartidas por varias autoridades y administradas por una de ellas, lo cual puede evidenciarse en los portales Web de las entidades del sector central, que incorporan servicios de las entidades adscritas o vinculadas a ellas. ${ }^{54}$

D) Las sesiones virtuales de comités, consejos, juntas y demás organismos colegiados

Conjuntamente con estas disposiciones, el artículo 63 autoriza a los comités, consejos, juntas y demás organismos colegiados en la organización interna de

documento original, siempre que se cumplan los requisitos exigidos por las leyes procesales y se garantice la autenticidad, integridad e inalterabilidad de la información [...]".

${ }^{54}$ Las páginas Web de los Ministerios suelen incorporar enlaces y/o contenidos propios de los servicios de sus entidades adscritas y vinculadas a modo de sistema informático integrado. 
las autoridades, para deliberar, votar y decidir en conferencia virtual, utilizando los medios electrónicos idóneos y dejando constancia por ese medio con los atributos de seguridad necesarios. Lo anterior significa que la práctica de concejos municipales, juntas administradoras locales, comités y cualquier otro organismo colegiado de la administración puede llevarse a cabo en estas condiciones, y por analogía esta norma podría aplicarse a las autoridades que no actúan colegiadamente, siempre que guarden protocolos similares de seguridad de la información.

\section{E) Publicación de actos administrativos}

Revoluciona la norma del artículo 65 del Código al sustituir el diario oficial de publicación de los actos administrativos de carácter general en aquellas entidades administrativas que no cuentan con órganos oficiales de publicidad o gacetas, pudiendo en estos casos la entidad respectiva hacer uso de su página electrónica en tanto este medio garantice amplia divulgación. Como deja entrever la norma, nuevamente la atención de la ley se concentra en la vigencia de los principios de eficacia, publicidad, celeridad y contradicción de las actuaciones administrativas, independientemente del medio usado.

\section{Conclusiones}

El impacto de la globalización y de la integración económica en sus perspectivas regional e interregional en el derecho administrativo colombiano se evidencia a través de la implementación y modificación de su legislación interna, adaptándose a la tendencia del hemisferio.

Por mandato constitucional, el legislador colombiano tiene amplias facultades para generar acuerdos de cooperación y liberalización de mercados que propendan por generar desarrollo, con las únicas limitaciones que le imponen la soberanía nacional y las competencias de las autoridades nacionales y territoriales en su respectiva jurisdicción.

En lo referente a la regulación del mercado y la integración económica, en Colombia el régimen de libertad es la regla general, por lo cual el Estado sólo intervendrá en la economía cuando sea estrictamente necesario para proteger los intereses de la parte que se encuentre en desventaja, lo que genera confianza y estabilidad jurídica para que el sector inversionista realice diversos negocios en la región. 
Un indicador que corrobora esta afirmación es la contratación pública como una herramienta jurídica de la globalización, porque atrae la inversión extranjera para la implementación de diversos proyectos que optimizan la función administrativa, y a su vez generan la competitividad y el posicionamiento del mercado colombiano con impacto directo sobre el PIB. Esta afirmación además ha tomado fuerza por causa de la negociación y ratificación reciente de varios tratados de libre comercio celebrados con la Unión Europea y Estados Unidos, entre otros países, con el objeto de ampliar las relaciones comerciales y diplomáticas a un escenario contemporáneo internacional.

Otra consecuencia importante del movimiento globalizador e integracionista en el derecho administrativo colombiano y en el ejercicio de la función administrativa es fomentar la eficacia de la gestión pública mediante la optimización de la interacción entre la administración pública y los asociados, lo cual se materializa con la regulación del Decreto-Ley Antitrámites que reduce la intervención policiva del Estado sobre el comportamiento de los particulares, mediante la eliminación de procedimientos que dilataban las actuaciones de los administrados ante el Estado.

Puede también afirmarse que otra manifestación de la globalización del derecho administrativo colombiano se encuentra en la incorporación gradual de las tecnologías de la información y las comunicaciones TIC a la ejecución de la función administrativa. Uno de los programas principales usados en pos de modernizar la función desempeñada por todas las autoridades del sector central de la administración se denomina "Gobierno en línea", consolidado como una herramienta de servicio al ciudadano que facilita su participación a través de mecanismos flexibles y ágiles que permitan una retroalimentación permanente con la administración en la prestación de servicios y la atención de peticiones, quejas y reclamos o recursos $(\mathrm{PQR})$, y la consulta de trámites ante la administración.

En síntesis, a través de las líneas de este trabajo puede evidenciarse, considerando los cambios históricos acaecidos a partir de la liberalización económica y la apertura de los mercados, que el derecho administrativo colombiano no desatendió la tendencia globalizadora impulsada en parte por el ideal integracionista propio del comercio mundial. Siendo por demás un mandato constitucional, la integración ha traído consigo la implementación del uso de las TIC en la función administrativa, el desarrollo de políticas de fomento económico, la celebración de tratados de libre comercio y acuerdos de cooperación, entre otros hechos de suma relevancia histórica.

Es obligado afirmar que en las últimas dos décadas el impacto de la integración regional en los ámbitos social, cultural y económico en Colombia y la región es destacado, en tanto la forma en que las administraciones interactúan con 
sus asociados y con otras jurisdicciones ha evolucionado mediante la incorporación de nuevas tecnologías, la creciente expansión de áreas de libre comercio, y un estímulo constante del diálogo político multilateral. Con ello, las normas que rigen la contratación estatal, los procesos de selección, los trámites ante el Estado, el comercio y las demás relaciones, como se evidencia en este estudio, se han reformado en búsqueda de la vigencia de los principios de eficiencia y eficacia para posibilitar el ejercicio de la función administrativa del Estado en un contexto de contemporaneidad.

Con los avances reseñados, los retos de los Estados en vía de desarrollo son constantes, y la voluntad política juega un papel importante para visibilizar, reconocer y estimular el acceso de todos los sectores y actores a un Estado visto como una gran empresa que es necesario administrar según las necesidades de la globalización. 